Check for updates

Cite this: RSC Adv., 2017, 7, 41460

Received 13th May 2017

Accepted 27th July 2017

DOI: $10.1039 / \mathrm{c} 7 \mathrm{ra0} 5413 \mathrm{k}$

rsc.li/rsc-advances

\section{Promotion of hydrogenation activity and sulfur resistance over Ni/ASA catalyst by support modification simultaneously with $\mathrm{P}$ and USY $\uparrow$}

\begin{abstract}
Sha Cui, Jiaqi Ge, Genggeng Wang, Ying Yang and Baijun Liu (DD *
Individual and simultaneous $\mathrm{P}$ and USY promoted amorphous $\mathrm{SiO}_{2}-\mathrm{Al}_{2} \mathrm{O}_{3}$ (ASA) supported $\mathrm{Ni}$ catalysts were prepared using the hydrothermal synthesis method with the assistance of cis-9-octadecenylamine. The catalysts were characterized by X-ray diffraction (XRD), $\mathrm{N}_{2}$-adsorption and desorption, UV-vis diffuse reflectance spectroscopy, FTIR spectroscopy of adsorbed pyridine (Py-IR), transmission electron microscopy (TEM), temperature-programmed hydrogen reduction $\left(\mathrm{H}_{2}-\mathrm{TPR}\right)$ and $\mathrm{X}$-ray photoelectron spectroscopy (XPS). The effects of $\mathrm{P}$ and USY loading on the activity of naphthalene hydrogenation were evaluated in a fixed bed reactor under the following reaction conditions: $P=4 \mathrm{MPa}, \mathrm{GHSV}=16 \mathrm{~h}^{-1}, \mathrm{H}_{2} /$ oil $=600$ volume ratio, $T=200,240,280$ and $320{ }^{\circ} \mathrm{C}$. Experimental results verified that all individual $\mathrm{P}$ and USY modified catalysts displayed higher hydrogenation activity than the freely $\mathrm{P}$ and USY decorated catalyst at 200-280 ${ }^{\circ} \mathrm{C}$. Furthermore, the catalyst simultaneously modified with $1.0 \mathrm{wt} \% \mathrm{P}$ and $10 \mathrm{wt} \%$ USY had the highest hydrogenation activity and sulfur tolerance. Multiple effects, such as metal dispersion, acid amount, surface exposure of the active $\mathrm{Ni}^{\circ}$ species and the $\left[\mathrm{Ni}_{\mathrm{Oh}}{ }^{2+}\right] /\left[\mathrm{Ni}_{\mathrm{Td}}{ }^{2+}\right]$ ratio were responsible for the high hydrogenation activity of $\mathrm{P}$ and USY-promoted catalysts.
\end{abstract}

\section{Introduction}

Aromatics in diesel, particularly polycyclic aromatic hydrocarbons (PAHs), can not only result in potential hazardous and carcinogenic effects, ${ }^{1}$ but can also increase the particle emissions from diesel engines, a primary factor in the elevation of the PM2.5 value ${ }^{2,3}$ and nitrogen oxides in the exhaust gas of automobiles. It is well known that when the aromatic content increases from $10 \%$ to $35 \%$, particle emissions increase from $8.1 \%$ to $12.9 \%$; moreover, hydrocarbons (HC), CO and $\mathrm{NO}_{x}$ emissions also grow. Moreover, the aromatics widely distributed in diesel fuel seriously influence its quality, resulting in poor combustion performance and low cetane number $(\mathrm{CN}) \cdot{ }^{4}$ Cooper et al. ${ }^{5}$ found that the cetane number of diesel fuel increased from 37 at an aromatic content of $37 \%$ to 48 when the aromatic content decreased to $20 \%$. Therefore, the content of PAHs decreased from $11 \%$ in the European standard V to less than $7 \%$ in the European standard VI. It was reported that more than $30 \%$ of the diesel fuels in our country come from fluid catalytic cracking diesel oil (FCC) whose density is high and cetane number is low, which is due to over $70 \%$ aromatics existing in FCC diesel oil; thus, it is vital to decrease aromatic content.

State Key Laboratory of Heavy Oil Processing, College of Chemical Engineering, China University of Petroleum, Beijing 102249, People's Republic of China. E-mail: bjliu2017@163.com; Tel: +8618911226182

$\dagger$ Electronic supplementary information (ESI) available. See DOI: 10.1039/c7ra05413k
Catalytic hydrogenation to reduce aromatic content is the most efficient route ${ }^{6,7}$ and is also commonly used in industry. Hydrofining and hydrocracking are the two main methods for hydrogenation at home and abroad. Although the cetane value of diesel oil can be increased to a great extent by hydrocracking, the relatively low yield, high hydrogen consumption and expensive operating costs make hydrocracking disadvantageous. Therefore, hydrofining is still an important technique in removing aromatics.

Typically, transition metal catalysts supported on alumina are applied to the hydrogenation process. However, alumina, due to low Brønsted acidity ${ }^{8}$ and overly strong metal-support interaction, ${ }^{9}$ which decreases the reducibility and prevents the formation of active phases in the corresponding catalyst, has been replaced by other supports. ${ }^{\mathbf{1 0}}$ In this sense, amorphous silicaalumina (ASA), as a composite carrier, possesses more acid sites ${ }^{\mathbf{1 1}}$ and mezzo metal-support interaction, ${ }^{\mathbf{1 2}}$ and its preparation procedure is simple, and the preparation cycle is short; thus, it is often applied to hydrogenation. There have been some studies $^{\mathbf{1 3 , 1 4}}$ that have provided evidence that ASA supported catalysts exhibit higher hydrogenation activity and improved sulfur tolerance relative to alumina supported catalysts.

Molecular sieves with high surface area and proper pore size as well as more acid sites are also potential supports of hydrogenation catalysts. ${ }^{\mathbf{1 5 - 1 7}}$ Although hydrogenation activity was enhanced on zeolite supported catalysts, coke formation and overcracking were boosted due to the greater number of acid sites on zeolite. ${ }^{16}$ Moreover, a composite ASA-USY (ultra-stable 
Y zeolite) material used for the hydrocracking process has been reported, since it combines the advantages of the $\mathrm{Y}$ zeolite and ASA, obtaining modified acid properties and pore structure and providing high activity. ${ }^{18,19}$ Moreover, the aromatic hydrogenation activity of an alumina supported noble metal catalyst was also promoted by the addition of USY due to high acidity and metal dispersion. ${ }^{20}$ This prompted us to study the naphthalene hydrogenation reaction using the ASA support by adding a small amount of USY under the precondition of no cracking. It is also well known that phosphorus, as a type of catalytic additive, can change the characteristics of catalysts, such as surface acidity, metal dispersion and metal electro negativity, followed by altering hydrogenation activity. ${ }^{21-23}$ However, the $\mathrm{P}$ effect on the hydrogenation process is still controversial. Some literature studies reported that the influence of phosphorus is not detectable or negative. ${ }^{\mathbf{2 4 , 2 5}}$ Other studies reported a positive effect of $\mathrm{P}$ addition to alumina ${ }^{25-27}$ or mesoporous silica ${ }^{28,29}$ supported catalysts, particularly for the hydrodesulfurization (HDS) and the hydrodenitrogenation (HDN) reactions.

Even though the USY and P modification in catalysts is found to have some effects on the hydrogenation process, there are no studies for individual and simultaneous USY and $\mathrm{P}$ modified nickel catalysts using amorphous $\mathrm{SiO}_{2}-\mathrm{Al}_{2} \mathrm{O}_{3}$ (ASA) as supports. In previous studies, several authors have suggested that macromolecular surface active or dispersion agents, such as Tween-80 (T-80), polyethylene glycol (PEG), polyvinyl alcohol (PVA) and polyoxyethylene octyl phenol ether-10 (OP-10) et al., could be added to the catalysts to efficiently improve dispersion and catalytic activity. Furthermore, the addition of chelating agents to enhance dispersion through the formation of clathrates with the metal to improve catalytic activity was also studied. In addition, Daniele Nicosia and Roel Prins ${ }^{\mathbf{3 0}}$ also found that the synergistic effect of phosphorus and glycol additives was more favorable for HDS.

Hence, in this present study, ASA materials with high specific surface area $\left(524 \mathrm{~m}^{2} \mathrm{~g}^{-1}\right)$ and large pore volume $\left(1.755 \mathrm{~cm}^{3} \mathrm{~g}^{-1}\right)$ were prepared in our laboratory, and the ASA supported nickel catalysts, by support modification with individual and simultaneous phosphorus and USY, were prepared using the hydrothermal synthesis method with the assistance of cis-9octadecenylamine. cis-9-Octadecenylamine, as a coordination and surface active agent, can form a Ni-cis-9-octadecenylamine complex with a nickel salt under hydrothermal condition, which boosts the dispersion of nanoparticles. Several authors have successfully prepared the metal oxide, ${ }^{31}$ noble metal ${ }^{32}$ and nickel phosphide nanoparticles ${ }^{33,34}$ with better dispersion using the hydrothermal method with the assistance of cis-9-octadecenylamine. The influence of the ASA support modification with individual and simultaneous phosphorus and USY was tested on naphthalene hydrogenation and sulfur tolerance of the nickel catalysts and correlated with physical-chemical properties.

\section{Experimental}

\subsection{Support preparation}

A procedure for the synthesis of ASA involved the following steps: with continuous stirring, an $\mathrm{Al}_{2}\left(\mathrm{SO}_{4}\right)_{3}$ solution and
$\mathrm{NH}_{3} \cdot \mathrm{H}_{2} \mathrm{O}$ were simultaneously added to a bath solution with optimal $\mathrm{pH}$, yielding an alumigel precipitate. After that, the water glass was added and the sample was transferred to a stainless-steel autoclave of seal aging at $80{ }^{\circ} \mathrm{C}$ for $3 \mathrm{~h}$. This seal aging process helps to stabilize the $\mathrm{pH}$ value of the system. Next, the sample was filtered, washed and dried to obtain amorphous silica-alumina (ASA) with a Si/Al molar ratio of 1.5. The support modified with USY (Si/Al molar ratio $=15,522 \mathrm{~m}^{2} \mathrm{~g}^{-1}$, $0.659 \mathrm{~cm}^{3} \mathrm{~g}^{-1}$ ) was prepared by mechanically blending USY and ASA. The as-prepared ASA and ASA-USY were mixed with the right amount of binders, adhesives and distilled water according to a certain mixing ratio, extruded, dried and calcined at $500{ }^{\circ} \mathrm{C}$ for $3 \mathrm{~h}$. The calcined materials were ground and screened to select 20-40 mesh objective particles. Furthermore, the P-doped ASA and ASA-USY supports were prepared by the saturated volume impregnation method. In detail, the ASA and ASA-USY supports were impregnated with aqueous solutions of $\left(\mathrm{NH}_{4}\right)_{2} \mathrm{HPO}_{4}$ with various P loadings. After the impregnation was completed, the samples were dried at $120{ }^{\circ} \mathrm{C}$ for $12 \mathrm{~h}$ and finally calcined at $500{ }^{\circ} \mathrm{C}$ for $3 \mathrm{~h}$.

\subsection{Catalyst preparation}

The catalysts were prepared via the hydrothermal synthesis method with the assistance of cis-9-octadecenylamine. The preparation was as follows: $10.96 \mathrm{~g} \mathrm{Ni}\left(\mathrm{NO}_{3}\right)_{2} \cdot 6 \mathrm{H}_{2} \mathrm{O}$ was dissolved in $50 \mathrm{~mL}$ deionized water and ethanol solution in an autoclave, and then a more substantial amount of mixture solution of cis-9-octadecenylamine and ethanol was added to the nickel nitrate solution under rotation. After the homogeneous mixed solution was formed, $20 \mathrm{~g}$ of support was added. Next, the autoclave was heated to $150{ }^{\circ} \mathrm{C}$ and leveled off for $12 \mathrm{~h}$ under sealing. Finally, the obtained composite was filtered, washed, dried and calcined at $500{ }^{\circ} \mathrm{C}$ for $3 \mathrm{~h}$ to obtain the oxidic catalyst. Herein, the catalysts with $\mathrm{P}$ loading of $0.0 \mathrm{wt} \%$, $0.5 \mathrm{wt} \%, 1.0 \mathrm{wt} \%, 1.5 \mathrm{wt} \%$ and $2.0 \mathrm{wt} \%$ were labeled as Cat, Cat-0.5P, Cat-1.0P, Cat-1.5P and Cat-2.0P, respectively, the catalysts with a USY content of $10 \mathrm{wt} \%$ and $20 \mathrm{wt} \%$ were denoted as Cat-10USY and Cat-20USY, respectively, and the catalyst modified with $1.0 \mathrm{wt} \% \mathrm{P}$ and $10 \mathrm{wt} \%$ USY simultaneously was denoted as Cat-1.0P-10USY, where the initial $\mathrm{Ni}$ loading was fixed at $10 \mathrm{wt} \%$ in all catalysts.

\subsection{Catalyst characterization}

XRD analysis was performed using a Bruker AXSD8 Advance Xray diffractometer with nickel-filtered $\mathrm{Cu} \mathrm{K} \alpha \mathrm{X}$-ray radiation at $40 \mathrm{kV}$ and $30 \mathrm{~mA}$. The $2 \theta$ range was scanned from $10^{\circ}$ to $80^{\circ}$ with a scanning rate of $2^{\circ} \mathrm{min}^{-1}$. The assignment of crystalline phases is on the basis of the powder diffraction file cards. The dispersion is decided by the altitude of the diffraction peak.

The specific surface area, pore volume and pore size were determined using a Bilder KuboX1000 system from the nitrogen adsorption-desorption isotherms at liquid nitrogen temperature. Prior to the measurement, the samples were outgassed in vacuum at $300{ }^{\circ} \mathrm{C}$ for $3 \mathrm{~h}$. The specific surface area is determined based on the theory of BET. The total pore volume of micropores and mesopores was calculated from the amounts of 
nitrogen adsorbed at $P / P_{0}=0.98$. Moreover, the pore size is obtained using the BJH method.

The UV-vis diffuse reflectance spectroscopy (DRS) was conducted on a UV-vis spectrophotometer (Hitachi U-4100) with an integration sphere diffuse reflectance attachment. Before measurement of the catalysts, the pure ASA support was tested. Then, the powder catalysts were placed into a quartz cell and the spectra were recorded in $200-800 \mathrm{~nm}$ with the ASA support as the baseline.

Temperature-programmed ammonia desorption ( $\left.\mathrm{NH}_{3}-\mathrm{TPD}\right)$ and temperature-programmed hydrogen reduction $\left(\mathrm{H}_{2}-\mathrm{TPR}\right)$ of the catalysts were measured on a TP 5079 analyzer. $\mathrm{NH}_{3}-\mathrm{TPD}$ is used to examine the acidity, and $\mathrm{H}_{2}$-TPR is carried out to analyze the reducibility of all oxidative catalysts. A total of $200 \mathrm{mg}$ of catalyst was placed in a quartz reactor and pretreated at $400{ }^{\circ} \mathrm{C}$ to remove surface adsorption of impurities. The pretreated catalysts were exposed to ammonia for $20 \mathrm{~min}$ at $30{ }^{\circ} \mathrm{C}$ to ensure adsorption saturation. When the weakly adsorbed ammonia was removed, the $\mathrm{NH}_{3}$-TPD profile was recorded from $100{ }^{\circ} \mathrm{C}$ to $600{ }^{\circ} \mathrm{C}$ at a heating rate of $10{ }^{\circ} \mathrm{C} \mathrm{min}{ }^{-1}$. For the TPR measurement, after the samples were pretreated, the $200 \mathrm{mg}$ catalysts were reduced in situ in flowing $5 \% \mathrm{H}_{2} / \mathrm{Ar}$ by heating from ambient temperature to $850{ }^{\circ} \mathrm{C}$ at a constant rate of $10{ }^{\circ} \mathrm{C} \mathrm{min}^{-1}$. Then, the TPR profiles were completed.

Fourier transform infrared spectroscopy analysis of adsorbed pyridine (Py-IR) was carried out using a Magna-IR 560 ESP spectrophotometer. The catalysts were pretreated for $1 \mathrm{~h}$ at $400{ }^{\circ} \mathrm{C}$ in vacuum and then cooled to $100{ }^{\circ} \mathrm{C}$ for pyridine adsorption. Py-IR spectra were recorded in the range of 1600$1400 \mathrm{~cm}^{-1}$ at 200 and $350{ }^{\circ} \mathrm{C}$. The data obtained at $200{ }^{\circ} \mathrm{C}$ are categorized as total acid and $350{ }^{\circ} \mathrm{C}$ as the medium and strong acid.

The morphologies and dispersion of active metals were acquired on a JEM-2100 $\mathrm{LaB}_{6}$ high resolution transmission electron microscope equipped with maximum acceleration voltage of $200 \mathrm{kV}$, amplification factor of $50 \times-1500 \times$, sample maximum inclination angle of $\pm 35^{\circ}$ and energy spectrometer element of 5 B-92 U. Prior to analysis, the sample was scattered around the ethanol solution, treated for 15-20 min via ultrasonication and suspended on the thin carbon film.

$\mathrm{X}$-ray photoelectron spectroscopy was carried out using a Thermo Fisher K-Alpha X-ray photoelectron spectrometer with an optimum analytical vacuum of $5 \times 10^{-9} \mathrm{mbar}$ in the analysis room. The data obtained were analyzed with peak fitting using XPSPEAK software. The binding energy was adjusted relative to $\mathrm{C} 1 \mathrm{~s}=284.6 \mathrm{eV}$.

\subsection{Catalytic tests}

The catalytic activity in naphthalene hydrogenation was measured at the total pressure of $4 \mathrm{MPa}$ carried out in a medium pressure fixed bed reactor in continuous down-flow mode using a model liquid feed comprising $6.5 \mathrm{wt} \%$ naphthalene in the $n$ decane solvent in the absence and presence of sulfur in the form of DBT. Fresh catalysts with the same volume of $5 \mathrm{~mL}$, which were diluted with inert alumina pellets, were used per run.
Prior to the hydrogenation reaction, the calcined catalysts were in situ reduced under $60 \mathrm{~mL} \mathrm{~min}{ }^{-1}$ of pure $\mathrm{H}_{2}(1 \mathrm{~atm})$ at $500{ }^{\circ} \mathrm{C}$ for $3 \mathrm{~h}$. After reduction, the reactor was cooled in flowing hydrogen to the specified reaction temperature, and then the hydrogen flow was regulated to $150 \mathrm{~mL} \mathrm{~min}^{-1}$ and the pressure was increased to $4 \mathrm{MPa}$. The reaction feed was introduced to the reactor at a constant rate of $15 \mathrm{~mL} \mathrm{~h}^{-1}$. The collected liquid products were analyzed online by an SP3420 gas chromatograph equipped with a FID detector and an SE-30 capillary column $(50 \mathrm{~m} \times 0.25 \mathrm{~mm} \times$ $0.5 \mu \mathrm{m})$. Only tetralin, trans-decalin, cis-decalin and the remaining naphthalene were detected in the products. Herein, the conversion of naphthalene and the selectivity of decalin were calculated according to the following equations:

$$
\text { Conversion }\left(\mathrm{wt}^{\mathrm{O}} \%\right)=100 \times \frac{m_{\text {naphthalene(in) }}-m_{\text {naphthalene(out })}}{m_{\text {naphthalene(in) }}}
$$

$$
\text { Selectivity }\left(\mathrm{wt}^{\%} \%\right)=100 \times \frac{m_{\text {cis-decalin }}+m_{\text {trans-decalin }}}{m_{\text {naphthalene(in) }}-m_{\text {naphthalene(out) }}}
$$

where $m$ stands for the mass fraction derived from the GC results.

\section{Results and discussion}

\subsection{Effect of individual $P$ and USY content on naphthalene hydrogenation}

Fig. 1 depicts the proposed road map of naphthalene hydrogenation. Typically, the hydrogenation of naphthalene is a consecutive reaction process: first, is the conversion to tetralin, followed by the formation of decalin (cis-decalin and transdecalin). ${ }^{35}$ From the two most important points (1) increasing $\mathrm{CN}$ and (2) reducing particulate emission, decalin is more desired product compared to tetralin in diesel fuel. ${ }^{36}$ Thus, the conversion and selectivity of decalin are measured for evaluating naphthalene hydrogenation activity.

The influence of individual $\mathrm{P}$ and USY promotion versus reaction temperature on the hydrogenation activity in naphthalene hydrogenation is presented in Fig. 2 and 3. Moreover, the hydrogenation activity of the ASA supported Ni catalyst prepared by saturated volume impregnation without the assistance of cis-9-octadecenylamine (Cat-IM) is included in the ESI (Fig. S1†). It can be observed that Cat-IM shows a lower hydrogenation activity than Cat. As listed in TEM (Fig. S2 $\dagger$ ) and $\mathrm{H}_{2}$ TPR (Fig. S3†), Cat displays better dispersion, smaller particle size and greater reducibility, and thus a higher hydrogenation

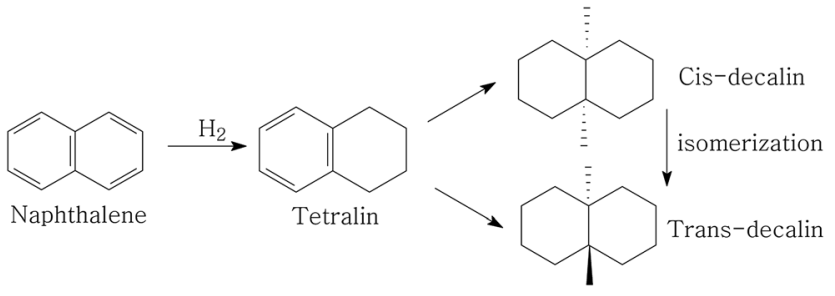

Fig. 1 A schematic for naphthalene hydrogenation. 


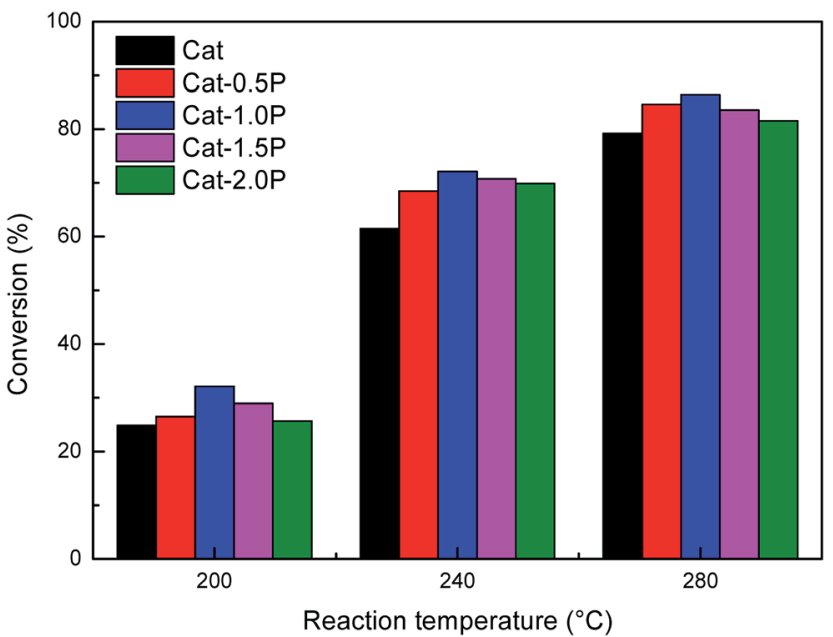

Fig. 2 Effect of $P$ content on the naphthalene hydrogenation activity at the reaction temperature of 200,240 and $280{ }^{\circ} \mathrm{C}$. Reaction conditions: $P=4 \mathrm{MPa}, \mathrm{GHSV}=16 \mathrm{~h}^{-1}, \mathrm{H}_{2} / \mathrm{oil}=600(\mathrm{v} / \mathrm{v})$.

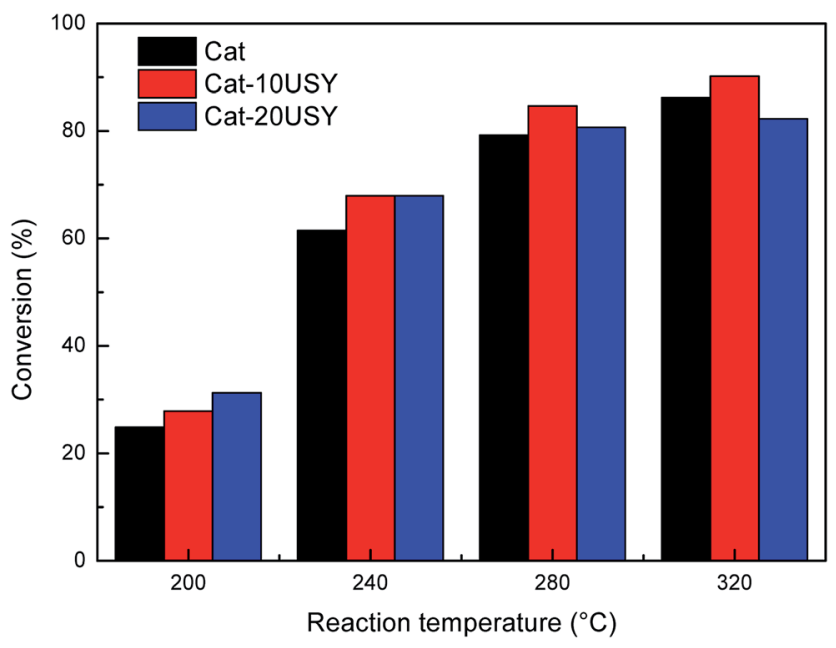

Fig. 3 Effect of USY content on the naphthalene hydrogenation activity at the reaction temperature of $200,240,280$ and $320{ }^{\circ} \mathrm{C}$. Reaction conditions: $P=4 \mathrm{MPa}, \mathrm{GHSV}=16 \mathrm{~h}^{-1}, \mathrm{H}_{2} / \mathrm{oil}=600(\mathrm{v} / \mathrm{v})$.

activity than Cat-IM. As seen in Fig. 2, regardless of the reaction temperature, all P-doped catalysts exhibit higher hydrogenation activity than the P-free one. The conversion increases with increased loading of phosphorus and reaches the optimum at $1.0 \mathrm{wt} \%$ in the support. The increased hydrogenation activity on $\mathrm{P}$ addition indicates that $\mathrm{P}$ is in favor of naphthalene hydrogenation. Moreover, the USY-promoted catalysts show a different naphthalene hydrogenation activity trend upon reaction temperature. At $200{ }^{\circ} \mathrm{C}$, the conversion still increases with increasing USY content. At $240{ }^{\circ} \mathrm{C}$, Cat-10USY and Cat-20USY display the same hydrogenation activity, which is higher than Cat. It is interesting that the maximum value in conversion is observed over the catalyst decorated with $10 \mathrm{wt} \%$ USY at a reaction temperature of $280{ }^{\circ} \mathrm{C}$. However, with the reaction temperature further increasing up to $320{ }^{\circ} \mathrm{C}$, the USY-free catalyst shows higher hydrogenation activity than the one comprising $20 \mathrm{wt} \%$ USY and lower than the catalyst with $10 \mathrm{wt} \%$ USY. This may be because support by modification with $20 \mathrm{wt} \%$ USY brings more strong acid sites that accelerate coke formation, thus hindering the hydrogenation process.

Briefly, the support simultaneously modified with $1.0 \mathrm{wt} \% \mathrm{P}$ and $10 \mathrm{wt} \%$ USY for Ni was prepared, and the catalyst was named as Cat-1.0P-10USY. Thus, the free-, individual P- and USY- as well as simultaneous P and USY modified catalysts were further studied in correlation with their physical-chemical properties and catalytic performance.

\subsection{Characterization of the Cat, Cat-1.0P, Cat-10USY and Cat-1.0P-10USY catalysts}

3.2.1. XRD. The XRD measurement patterns of the oxidic and reductive catalysts are presented in Fig. 4. All oxidic catalysts exhibit well-resolved XRD peaks of NiO, centered at 37.7, 43.4 and $62.7^{\circ}$, and no $\mathrm{P}_{2} \mathrm{O}_{5}$ characteristic peaks appear. Moreover, the USY-based catalysts also show the characteristics of the zeolite $\mathrm{Y}$ phase at $2 \theta=15.7,18.7,20.4,23.6,27.1,30.8$, 31.5 and $34.2^{\circ}$. Furthermore, as shown in the ESI (Fig. S4 $\dagger$ ), cis9-octadecenylamine participated in the preparation of the
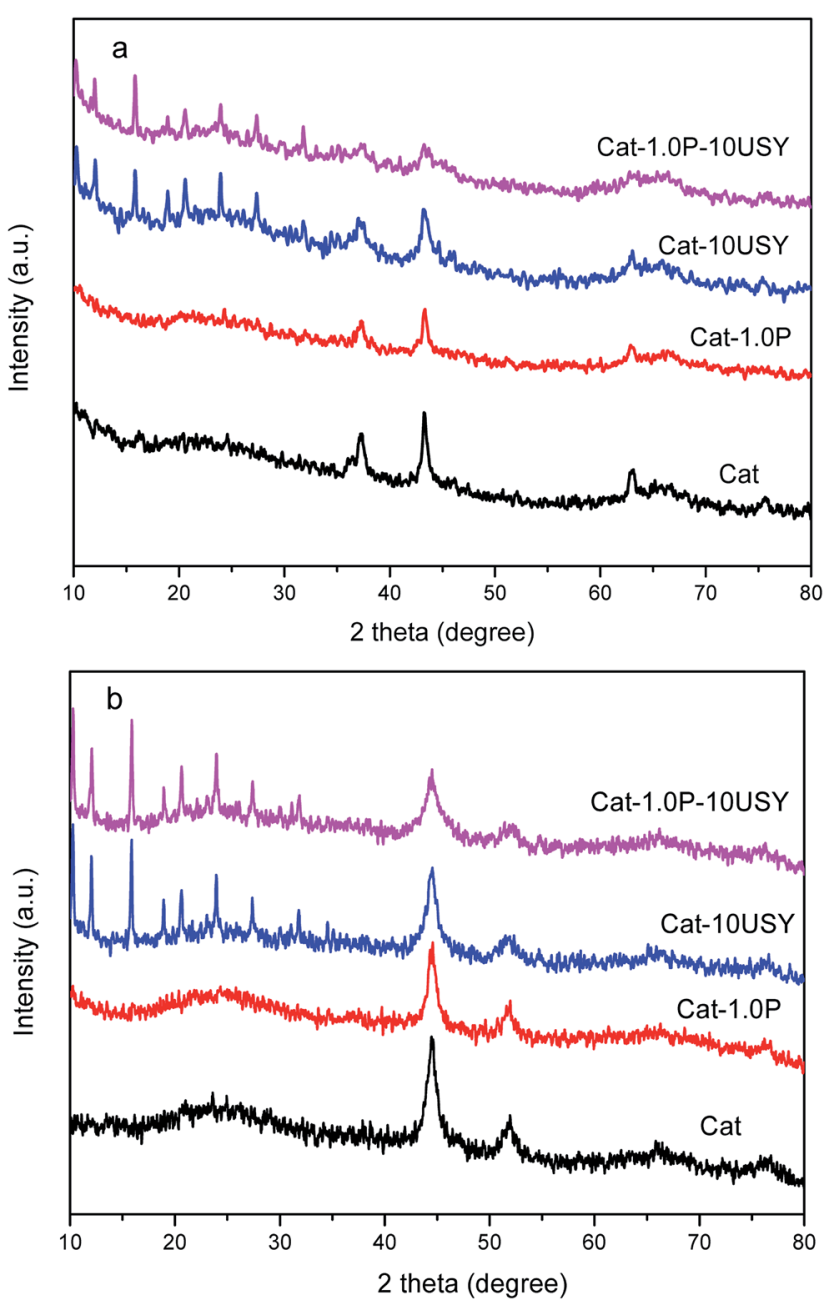

Fig. 4 X-ray powder diffractograms of the oxidic catalysts (a) and reductive catalysts (b). 

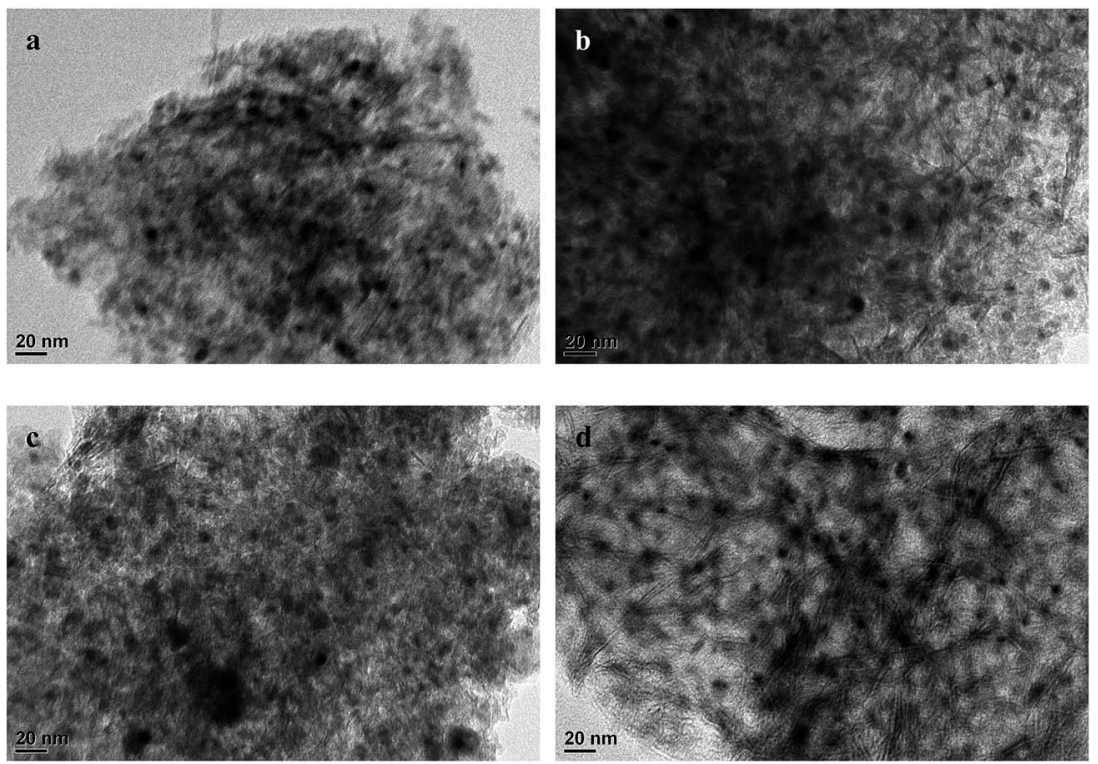

Fig. 5 TEM micrographs of the reductive catalysts: (a) Cat, (b) Cat-1.0P, (c) Cat-10USY, (d) Cat-1.0P-10USY.

Table 1 The textural parameters of catalysts

\begin{tabular}{|c|c|c|c|c|c|c|}
\hline Catalysts & $S_{\mathrm{BET}}{ }^{a}\left(\mathrm{~m}^{2} \mathrm{~g}^{-1}\right)$ & $V_{\text {total }}^{b}\left(\mathrm{~m}^{3} \mathrm{~g}^{-1}\right)$ & $V_{\text {micro }}\left(\mathrm{m}^{3} \mathrm{~g}^{-1}\right)$ & $V_{\text {meso }}\left(\mathrm{m}^{3} \mathrm{~g}^{-1}\right)$ & $d^{c}(\mathrm{~nm})$ & $d_{\mathrm{Ni}}^{d}(\mathrm{~nm})$ \\
\hline Cat & 375 & 0.987 & 0.158 & 0.829 & 10.52 & 9.8 \\
\hline Cat-1.0P & 336 & 0.917 & 0.142 & 0.775 & 10.92 & 9.5 \\
\hline Cat-1.0P-10USY & 358 & 0.939 & 0.167 & 0.772 & 10.22 & 6.0 \\
\hline
\end{tabular}

catalysts. It is considered that the cis-9-octadecenylamineassisted catalyst (take ASA supported nickel catalyst for example) is formed via the following process: Ni-cis-9-octadecenylamine complex/ASA (mixture process) $\rightarrow \mathrm{Ni}(\mathrm{OH})_{2} / \mathrm{ASA}$ (hydrothermal process) $\rightarrow \mathrm{NiO} / \mathrm{ASA}$ (calcination process) $\rightarrow \mathrm{Ni} /$ ASA (reduction process), as listed in Fig. S5. $\dagger$ As shown in Fig. 4(a), phosphorus addition reduces the intensity of the XRD peaks, suggesting that $\mathrm{P}$ is favorable to increase the dispersion of Ni species on the surface of ASA. Moreover, the characteristic peaks of $\mathrm{NiO}$ on the individual USY modified catalyst become slightly wider, implying a decreased particle size. As expected, much weaker and broader peaks are observed in the catalyst modified with simultaneous $\mathrm{P}$ and USY, suggesting better dispersion and smaller particle size compared to the other three catalysts. Fig. 4(b) shows the XRD diffraction peaks of the reductive catalysts. The peaks at 44.4 and $51.7^{\circ}$ due to $\mathrm{Ni}^{\circ}$ are clearly seen for all catalysts and the USY modified catalysts also show the characteristics of the zeolite Y phase. Similar to the oxidic catalysts, $\mathrm{P}$ and USY addition decreases the peak intensity, and the Ni peaks are broader in the USY modified catalysts. In sum, $\mathrm{P}$ addition increases dispersion, and USY addition not only promotes dispersion but also decreases particle size.
3.2.2. TEM. Representative transmission electron micrographs of all reductive catalysts are depicted in Fig. 5. The dark dots clearly seen on the catalysts are ascribed to Ni particles. All Ni particles exhibit global morphology. The particle aggregation that is formed on the ASA surface in Cat can result in restricted access to active sites. ${ }^{26}$ In contrast, the support modified with phosphorus improves metal dispersion. From Fig. 5(c), it is also seen that the Ni particle size of Cat-10USY is smaller compared to that in the free-USY decorated catalysts, which agrees with the XRD results; however, a certain degree of aggregation still appears, which may be attributed to some small pores due to USY leading to poor dispersion. The catalyst simultaneously decorated with $\mathrm{P}$ and USY shows better dispersion and smaller particle size. The average particle size of the catalysts $\left(d_{\mathrm{Ni}}\right)$ is obtained from TEM by taking 20-30 particles and is summarized in Table 1 . The mean particle diameter of different catalysts follows the sequence of Cat-1.0P-10USY $<$ Cat-10USY $<$ Cat$1.0 \mathrm{P}<$ Cat.

3.2.3. $\mathbf{N}_{2}$ adsorption-desorption. The $\mathrm{N}_{2}$ adsorptiondesorption isotherms (not shown here) of all catalysts are characteristic of mesoporous materials with H-IV hysteresis loops, which appear in the range of relative pressure from 0.5 to 1.0. The mean textural properties of the catalysts determined by 


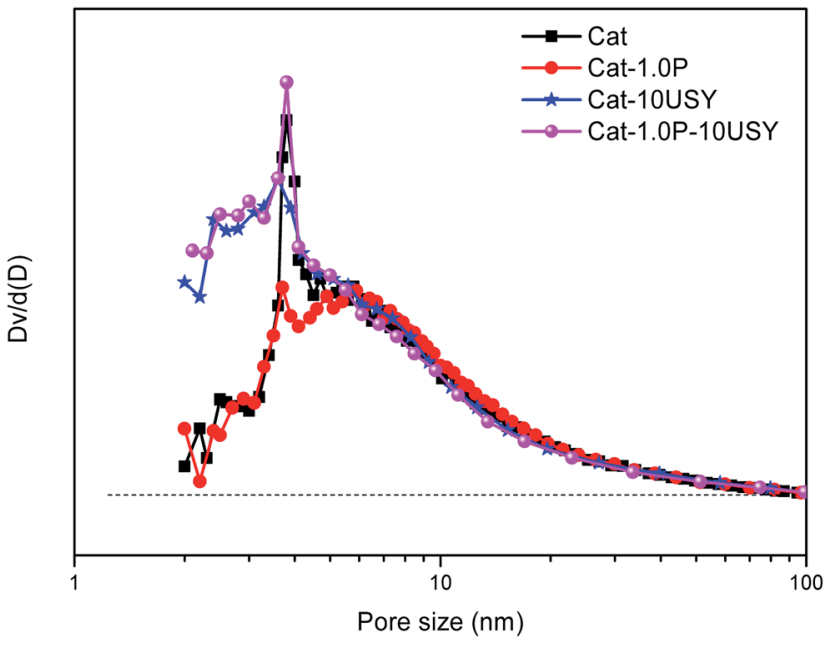

Fig. 6 Pore size distributions of all catalysts.

$\mathrm{N}_{2}$ adsorption-desorption, including specific surface area, pore diameter and pore volume, are summarized in Table 1 . As expected, in comparison with the P-free catalyst, phosphorus addition leads to a decrease in specific surface area as well as pore volume. In general, this decrease in specific surface area and pore volume is characteristic of a pore blockage phenomenon. ${ }^{26}$ Moreover, a slight increase in the mean pore diameter is obtained on Cat-1.0P, which may be because phosphorus, as a corrosive agent, can break some micropores of the support with a consequent increase in macroporosity ${ }^{37}$ also linked with the capillary force, prompting the phosphorus to be preferentially adsorbed in small pores. However, a trace increase or no difference in surface area is observed over Cat-10USY compared with Cat, which may be due to a similar specific surface area of USY with ASA. Furthermore, the total pore volume of Cat-10USY is lower than Cat, yet its micropore volume is largely higher than that of Cat, and this indicates a larger amount of micropore existing in the Cat-10USY. As shown in Fig. 6, the pore size distribution exhibits some small pores below $3 \mathrm{~nm}$ over Cat10USY and Cat-1.0P-10USY, which do not exist over Cat and Cat-1.0P. The Cat-1.0P-10USY catalyst has a medium textural property, including specific surface area, pore volume and pore diameter, between the Cat-1.0P and Cat-10USY catalysts.

3.2.4. UV-vis. The UV-vis DRS spectra of various catalysts after background removal of the ASA support are shown in Fig. 7. All catalysts exhibit a strong absorption band at 350$400 \mathrm{~nm}$ corresponding to the $\mathrm{Ni}^{2+}$ oxides in octahedral $(\mathrm{Oh})$ coordination. The adsorption bond strength follows the trend: Cat-1.0P-10USY $>$ Cat-1.0P $>$ Cat-10USY $\approx$ Cat. Cat, Cat-1.0P and Cat-10USY also display a faint absorption band at 550-650 nm, indicating that the nickel species are ascribed to tetrahedrally coordinated $\mathrm{Ni}^{2+}(\mathrm{Td})$. This demonstrates that parts of the $\mathrm{Ni}^{2+}$ species are transformed into $\mathrm{NiAl}_{2} \mathrm{O}_{4}$. Comparatively, the Cat1.0P-10USY catalyst presents no adsorption band at 550$650 \mathrm{~nm}$, indicating no existence of $\mathrm{NiAl}_{2} \mathrm{O}_{4}$ species, which evinces that simultaneous $\mathrm{P}$ and USY addition to the catalyst helps improve the metal-support interaction and a furtherance

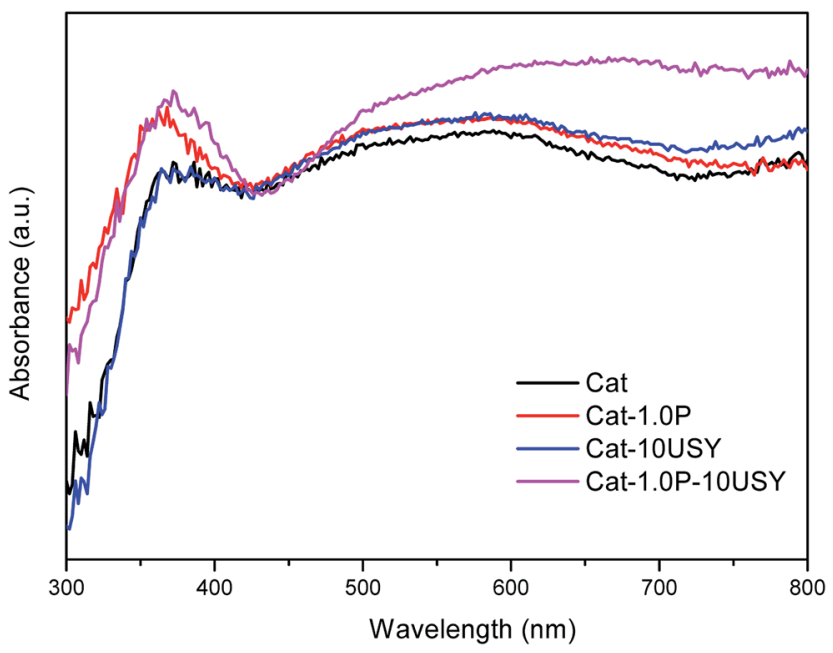

Fig. 7 UV-vis DRS spectra of oxidic catalysts.

of the formation of $\mathrm{Ni}^{2+}$ oxides in octahedral coordination. It is well known that the greater the $\left[\mathrm{Ni}_{\mathrm{Oh}}{ }^{2+}\right] /\left[\mathrm{Ni}_{\mathrm{Td}}{ }^{2+}\right]$ ratio, the higher is the catalytic activity. ${ }^{38}$

3.2.5. $\quad \mathrm{NH}_{3}$-TPD and Py-IR. Acid sites of various catalysts are measured by $\mathrm{NH}_{3}$-TPD and Py-IR, and the $\mathrm{NH}_{3}$-TPD profiles are presented in Fig. 8. The quantity of Brønsted and Lewis acid sites evaluated on the basis of the equations in the literature ${ }^{39}$ is summarized in Table 2. Cat shows a broad $\mathrm{NH}_{3}$ desorption peak at $250{ }^{\circ} \mathrm{C}$, implying the existence of main weak acid sites. Comparatively, there is a slight shift in the temperature of the peak maxima in the $\mathrm{NH}_{3}$-TPD profiles towards low temperature $\left(230^{\circ} \mathrm{C}\right)$ with the modification of $1.0 \mathrm{wt} \% \mathrm{P}$, and the peak area of Cat-1.0P is larger than that of Cat. This indicates that $\mathrm{P}$ addition mainly increases the weaker acid sites. The catalysts, by support modification with individual USY and simultaneous $\mathrm{P}$ and USY, exhibit two $\mathrm{NH}_{3}$ desorption peaks at lower $\left(200{ }^{\circ} \mathrm{C}\right)$ and higher $\left(300{ }^{\circ} \mathrm{C}\right)$ temperature, suggesting the coexistence of weak and medium strong acid sites. Referring to the P modified catalyst, the USY addition also increases some medium strong acid

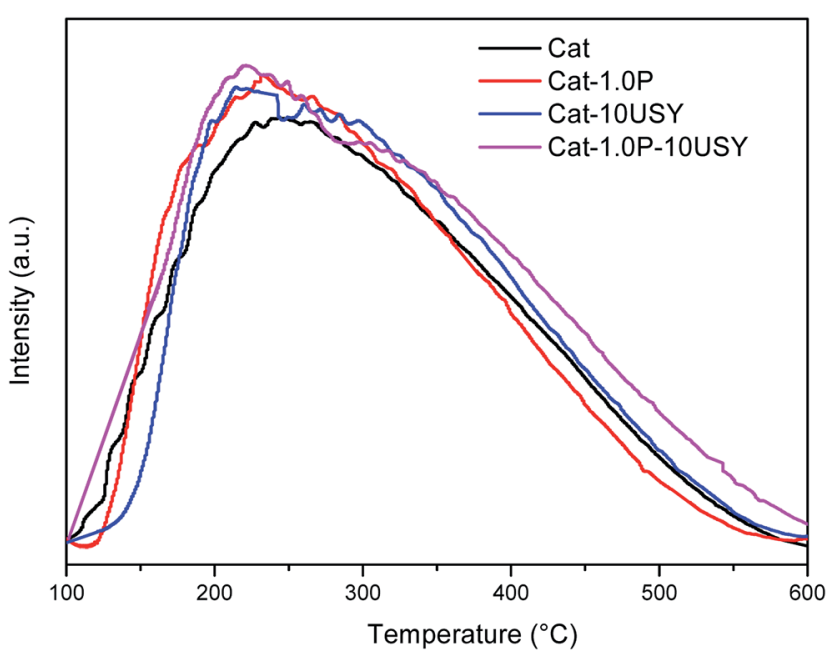

Fig. $8 \mathrm{NH}_{3}$-TPD of the catalysts. 
Table 2 The amounts and distribution of the acid sites of catalysts ${ }^{a}$

\begin{tabular}{|c|c|c|c|c|c|c|c|}
\hline \multirow{2}{*}{ Catalysts } & \multicolumn{7}{|c|}{ Amount $\left(\mu \mathrm{mol} \mathrm{g}{ }^{-1}\right)$ and distribution of acid sites } \\
\hline & \multicolumn{3}{|c|}{ Total acid $\left(\mu \mathrm{mol} \mathrm{g}{ }^{-1}\right)$} & \multicolumn{3}{|c|}{ Media and strong acid $\left(\mu \mathrm{mol} \mathrm{g}{ }^{-1}\right)$} & Weak/total acid \\
\hline Cat & 27 & 273 & 300 & 16 & 120 & 136 & 0.547 \\
\hline Cat-1.0P & 36 & 295 & 331 & 21 & 126 & 147 & 0.556 \\
\hline
\end{tabular}

amount, which is derived from the USY itself. As listed in Table 2, Py-IR results show that the total acid amount and weak/total acid ratio follows the trends: Cat-1.0P-10USY $>$ Cat-10USY $\approx$ Cat-1.0P $>$ Cat and Cat-1.0P $>$ Cat $>$ Cat-1.0P-10USY $>$ Cat-10USY, respectively. It is well known that the large specific surface area induces the increase of acid sites. ${ }^{40}$ Clearly, a decrease in the surface area is observed with the catalyst modified with $\mathrm{P}$, which cannot account for the increase in acid sites. Therefore, the greater acid amount of Cat-1.0P is explained with the principle of acid sites formation. In detail, phosphoric acid, as a product of decomposition of $\left(\mathrm{NH}_{4}\right)_{2} \mathrm{HPO}_{4}$ via heating, has three hydroxyl groups adhered to the phosphorus atom, which interact with the surface hydroxyls of alumina by a single bond. Therefore, the other two hydroxyl groups of $\mathrm{H}_{3} \mathrm{PO}_{4}$ remain unbound on the catalyst surface, which increase the number of hydroxyl groups on the catalyst surface and thus increase the acid sites. Due to the acidity strength of $\mathrm{Al}-\mathrm{OH}$ being higher than $\mathrm{P}-\mathrm{OH}$, phosphorus addition decreases the acid strength of the catalyst. Therefore, the catalyst modified with $\mathrm{P}$ alone also shows a high weak to total acidity ratio. The Cat-10USY catalyst has a larger acid amount than Cat, particularly Brønsted acid, which originates from the inherent acid sites of USY more than ASA, and shows a low weak to total acid ratio. As supposed, the Cat-1.0P-

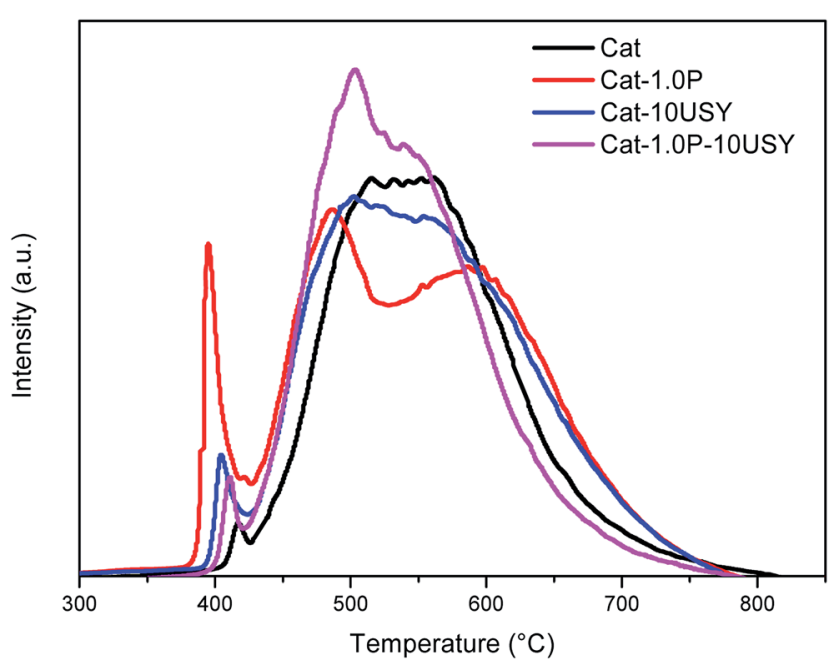

Fig. $9 \mathrm{H}_{2}$-TPR profiles of all calcined catalysts.
10USY catalyst presents the largest acid amount, which is promoted by $\mathrm{P}$ and USY simultaneously. The acid properties are correlated with the naphthalene hydrogenation activity as well as the sulfur tolerance of catalysts.

3.2.6. $\quad \mathbf{H}_{2}$-TPR. Fig. 9 represents the typical $\mathrm{H}_{2}$-TPR profiles of all calcined catalysts. Different catalysts possess evidently different curve shape; however, each catalyst contains a shoulder peak centered at about $400{ }^{\circ} \mathrm{C}$, suggesting that there are certain amounts of nickel species that freely interact with the support. As seen, apart from the shoulder peak centered at $420{ }^{\circ} \mathrm{C}$, Cat also shows a broad peak at $500-600{ }^{\circ} \mathrm{C}$, which is due to the reduction of $\mathrm{Ni}^{2+}$ to $\mathrm{Ni}^{\circ}$, where $\mathrm{Ni}^{2+}$ interacts with the support. Compared to Cat, Cat-10USY presents a similar peak shape and a slightly larger peak area for the shoulder peak as well as a broader major peak, which indicates an increased amount of isolated NiO species. When $\mathrm{P}$ is added, three reduction peaks are clearly obtained, and the two larger peaks correspond to $\mathrm{NiO}$ species that interact weakly and strongly with the ASA support. It is further observed that the peak areas of the lower two peaks increased, which indicated that $P$ readily promotes the formation of isolated $\mathrm{NiO}$ and also NiO species with weak interaction with the support, which are more easily reduced to obtain $\mathrm{Ni}^{\circ}$ sites, real catalytically active sites. ${ }^{12} \mathrm{As}$ for the Cat-1.0P-10USY catalyst, more NiO species that interact weakly with the supports are obtained. This larger reducibility obtained over the decorated catalysts is related to the increase in dispersion of $\mathrm{NiO}$ on the surface of the support as well as a weakened metal-support interaction.

3.2.7. XPS. XPS analysis is performed in order to determine the different chemical states of the surface elements. Fig. 10 shows Ni $2 \mathrm{p}_{2 / 3}$ spectra of the reductive catalysts. All catalysts present two important peaks obtained by curve-fitting appearing at $853.06-853.57 \mathrm{eV}$ and $856.06-856.71 \mathrm{eV}$ with a satellite peak of 861.96-862.38 eV. The binding energies at 853.06$853.57 \mathrm{eV}$ are attributed to $\mathrm{Ni}^{\circ}$ and those at $856.06-856.71 \mathrm{eV}$ are characteristic of $\mathrm{Ni}^{2+}$ in the NiO species. ${ }^{41}$

It is universally known that the surface exposure of metal is related to the metal-support interaction and metal dispersion as well as the metal particle size and has effects on the catalytic activity. The fitted results of the XPS spectra, including Si/Al, $\mathrm{Ni}_{\text {total }} / \mathrm{Al}$ and $\mathrm{Ni}^{\circ} / \mathrm{Al}$ ratio, are listed in Table 3. As shown, derived from the $\mathrm{Ni}^{\circ} / \mathrm{Al}$ ratio, the surface exposure of the $\mathrm{Ni}^{\circ}$ species in four catalysts follows the sequence: Cat-1.0P-10USY > 

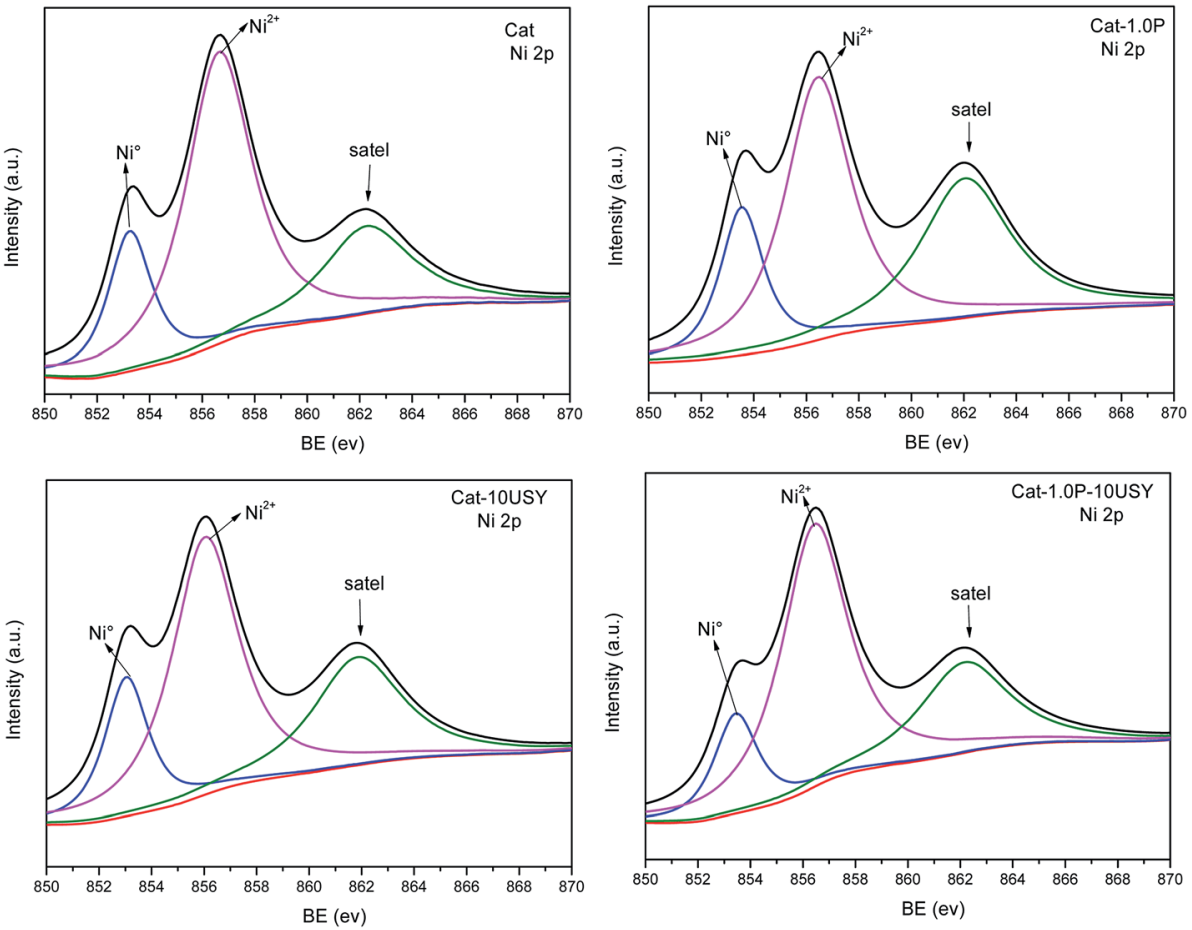

Fig. 10 XPS Ni $2 p_{2 / 3}$ spectra of the reductive catalysts.

Table 3 Fitting results of XPS on the reductive catalysts

\begin{tabular}{llll}
\hline Catalysts & $\mathrm{Si} / \mathrm{Al}$ & $\mathrm{Ni}_{\text {total }} / \mathrm{Al}$ & $\mathrm{Ni}^{\circ} / \mathrm{Al}$ \\
\hline Cat & 0.479 & 0.0614 & 0.0149 \\
Cat-1.0P & 0.633 & 0.0642 & 0.0175 \\
Cat-10USY & 0.444 & 0.1014 & 0.0269 \\
Cat-1.0P-10USY & 0.464 & 0.1342 & 0.0272
\end{tabular}

Cat-10USY > Cat-1.0P > Cat. The USY modified catalysts of Cat1.0P-10USY and Cat-10USY show evidently higher surface $\mathrm{Ni}^{\circ}$ species than Cat and Cat-1.0P, which should be due to the

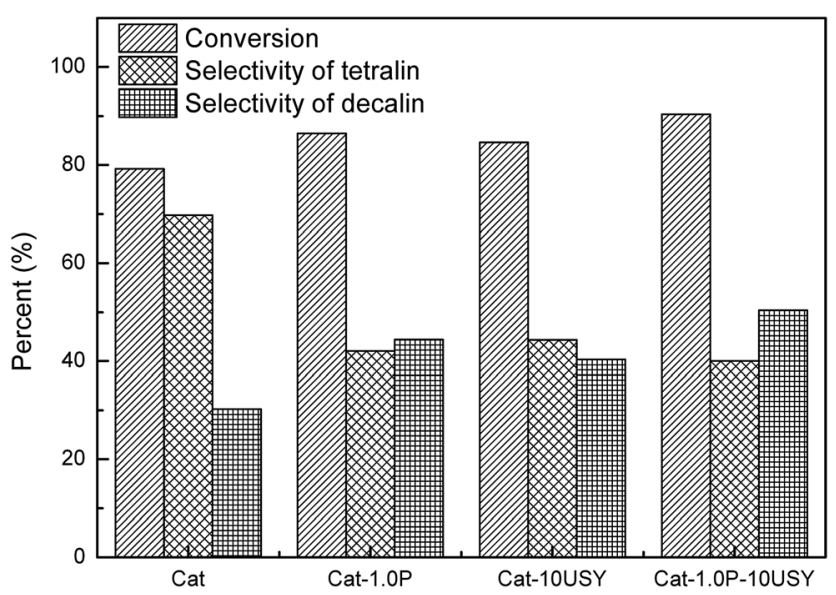

Fig. 11 Hydrogenation of naphthalene over different catalysts. Reaction conditions: $T=280^{\circ} \mathrm{C}, \mathrm{P}=4 \mathrm{MPa}, \mathrm{GHSV}=16 \mathrm{~h}^{-1}$ and $\mathrm{H}_{2} /$ oil $=$ $600(\mathrm{v} / \mathrm{v})$. former having smaller particle size, as evidenced in XRD and TEM results. Results of the higher exposure of $\mathrm{Ni}^{\circ}$ in Cat-1.0P than in Cat are obtained, because the former has better dispersion of nickel species supported on the $\mathrm{P}$ modified catalyst compared to the P-free one, as proved by $\mathrm{H}_{2}$-TPR.

\subsection{Comparison of the hydrogenation activity over the Cat, Cat-1.0P, Cat-10USY and Cat-1.0P-10USY catalysts}

The activities of four catalysts at $280{ }^{\circ} \mathrm{C}$ are presented in Fig. 11 . As shown, Cat shows a conversion of $79.24 \%$ and a selectivity to decalin of $30.26 \%$, which is lower than the other catalysts under the same conditions. Although Cat is provided with large specific surface area and pore volume as well as medium pore diameter, it performs poorly in the hydrogenation of naphthalene, which may be attributed to its low metal dispersion, surface exposure of $\mathrm{Ni}^{\circ},\left[\mathrm{Ni}_{\mathrm{Oh}}{ }^{2+}\right] /\left[\mathrm{Ni}_{\mathrm{Td}}{ }^{2+}\right]$ ratio and acid amount. The catalyst modified with $\mathrm{P}$ alone displays not only a higher activity $(86.45 \%)$ but also enhanced selectivity to decalin (42.4\%) compared to the P-free one. This is clearly observed in Fig. 2. Combined with the characteristic results above, it is not difficult to speculate that the higher activity of Cat-1.0P is linked with the good dispersion of metal and its decreased interaction with the support as well as the high acid amount. As observed from Table 2, a larger amount of acid sites, particularly for Brønsted acid sites are formed on Cat-10USY. As Aguayo ${ }^{42}$ and Wang $^{43}$ reported, Brønsted acid sites could promote the hydrogenation of aromatics. Combining XRD and TEM results, we observe that the nickel particles size over the USY modified catalyst is smaller, which could increase the surface area of the active sites. Therefore, the conversion and selectivity to decalin 
over Cat-10USY (84.66\% and $40.36 \%$ ) are enhanced with respect to Cat. The activity and selectivity of decalin over Cat-1.0P is slightly higher than Cat-10USY because the former has more $\mathrm{Ni}_{\mathrm{Oh}}{ }^{2+}$ species, which will be transformed into the metal active sites, as shown in the UV-vis results. Due to the combination of $\mathrm{P}$ and USY, the catalyst simultaneously decorated with $\mathrm{P}$ and USY shows high acid amount, reducibility, and $\left[\mathrm{Ni}_{\mathrm{Oh}}{ }^{2+}\right] /\left[\mathrm{Ni}_{\mathrm{Td}}{ }^{2+}\right]$ ratio as well as good dispersion and small metal particle size. These factors prompt Cat-1.0P-10USY to exhibit superior hydrogenation activity and selectivity to decalin $(90.38 \%$ and $50.38 \%)$.

\subsection{Comparison of the sulfur tolerance over the Cat, Cat- 1.0P, Cat-10USY and Cat-1.0P-10USY catalysts}

Other than the hydrogenation activity, the sulfur tolerance of the catalyst is also a pivotal evaluation criterion for the hydrotreating process in practical applications. In order to compare the sulfur tolerance of different catalysts, the feed containing 300 and $500 \mu \mathrm{g}$ per $\mathrm{g}$ sulfur, using dibenzothiophene as the sulfur compound, was employed. The activities of naphthalene hydrogenation over Cat, Cat-1.0P, Cat-10USY and Cat-1.0P10USY in the absence and presence of 300 and $500 \mu \mathrm{g}$ per $\mathrm{g}$ sulfur, at a steady temperature of $280{ }^{\circ} \mathrm{C}$, are summarized in Fig. 12.

Regardless of the catalysts tested, when DBT was added to the reaction feed, a decrease in naphthalene hydrogenation activity was observed. The influence of sulfur content in the naphthalene hydrogenation process over four catalysts was assessed using $300 \mu \mathrm{g}$ per $\mathrm{g}$ sulfur and $500 \mu \mathrm{g}$ per $\mathrm{g}$ sulfur. As predicted, the hydrogenation activity and selectivity of decalin in the feed containing $500 \mu \mathrm{g}$ per $\mathrm{g}$ sulfur is lower than that containing $300 \mu \mathrm{g}$ per $\mathrm{g}$ sulfur. This is due to a competitive adsorption between DBT and naphthalene. Taking the higher content of sulfur (500 $\mu \mathrm{g} \mathrm{g}^{-1}$ of S) for instance, Cat-1.0P-10USY has the highest activity, followed by the Cat-10USY, Cat-1.0P and Cat catalyst, and the conversion and selectivity of decalin decrease by $17.72 \%$ and $16.80 \%, 26.81 \%$ and $23.96 \%, 31.09 \%$ and $25.33 \%$ and $42.96 \%$ and $30.26 \%$, respectively. The activity trend is different from the one in the absence of DBT (Cat-1.0P10USY $>$ Cat-1.0P $>$ Cat-10USY $>$ Cat). This strongly indicates a great difference in sulfur tolerance over various catalysts.

As listed in Fig. 12, all modified catalysts show higher sulfur tolerance than the one with no modification, which is due to improved physical-chemical properties over the former, such as acid amount, metal dispersion and pore structure. A substantial amount of research ${ }^{5,35,44-46}$ related to sulfur tolerance improvement through more acid sites has been reported. Furthermore, since the dispersion of active metal is enhanced, which corresponds to the increase of surface area of active phases, the capacity to contain poison is increased, and a similar phenomenon has been reported by Song. ${ }^{47}$ As discussed above, the P-containing catalyst owns a larger acid amount and better dispersion and thus, an improved sulfur tolerance. The catalyst of Cat-10USY shows a lower hydrogenation activity in the absence of DBT but a slightly higher activity in the presence of DBT compared to Cat-1.0P. As listed in Fig. 5 and Table 2, Cat-
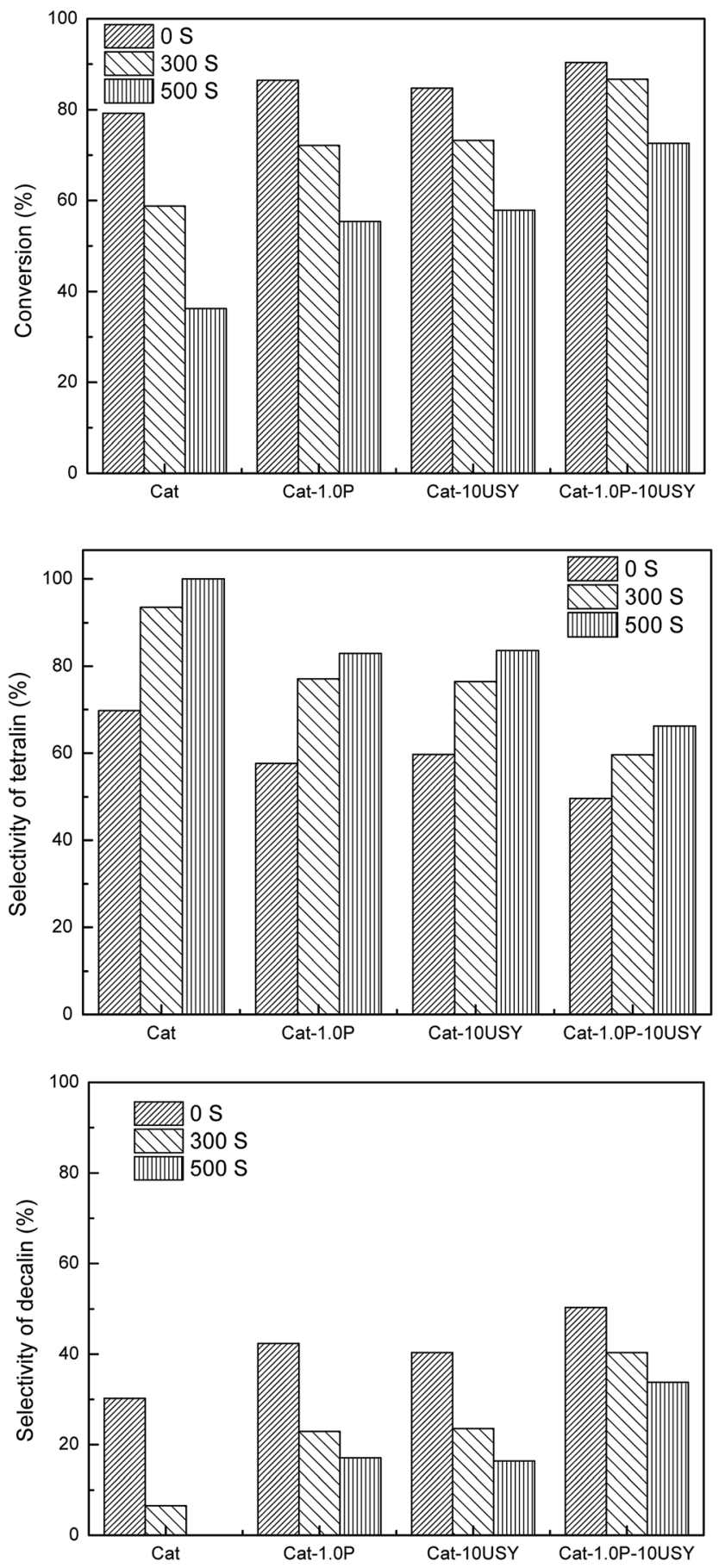

Fig. 12 Comparison of hydrogenation activity of naphthalene in the absence and presence of DBT for all catalysts. $0 \mathrm{~S}$ represents the feed without sulfur, and $300 \mathrm{~S}$ and $500 \mathrm{~S}$ stands for the feed comprised of $300 \mu \mathrm{g}$ per $\mathrm{g}$ sulfur and $500 \mu \mathrm{g}$ per $\mathrm{g}$ sulfur. Reaction conditions: $P=$ $4 \mathrm{MPa}, \mathrm{T}=280^{\circ} \mathrm{C}, \mathrm{GHSV}=16 \mathrm{~h}^{-1}$ and $\mathrm{H}_{2} /$ oil $=600(\mathrm{v} / \mathrm{v})$.

10USY has worse dispersion and a similar total acid amount as Cat-1.0P, but shows higher sulfur tolerance. This indicates that the prominent sulfur tolerance of the USY-containing catalyst is not only related to the total acid amount and metal dispersion but also more Brønsted acid sites and the hydrogen spillover effect. As various authors ${ }^{46,48,49}$ have reported, the resistance to sulfur increased with Brønsted acid sites. Moreover, in the USY 
modified catalyst, because of the coexistence of micropore and mesopore, the DBT could not access the Ni sites in the micropores. Hence, the active hydrogen would be formed on the sulfur free Ni sites and through the support bridge transferred to the nickel sites in the mesopores which are poisoned by sulfur. Then, the poisoned Ni sites would be partly recovered by hydrogen spillover, leading to an enhanced sulfur resistance. Accordingly, the greater improvement in sulfur tolerance due to the support simultaneously modified with $\mathrm{P}$ and USY is explained in terms of a multiple promotional effect of increased acid amount, particularly Brønsted acid amount, metal dispersion and hydrogen spillover.

\section{Conclusions}

The amorphous $\mathrm{SiO}_{2}-\mathrm{Al}_{2} \mathrm{O}_{3}$ (ASA) supported $\mathrm{Ni}$ catalysts was developed by support modification with individual and simultaneous incorporation of P and USY, and the catalysts were prepared using the hydrothermal synthesis method assisted by cis-9-octadecenylamine. The catalytic activities for naphthalene hydrogenation in the absence and presence of DBT were studied over free, individual and simultaneous $\mathrm{P}$ and USY promoted catalysts. All modified catalysts exhibited higher hydrogenation activity and selectivity of decalin than the freely $\mathrm{P}$ and USY decorated catalyst. When $\mathrm{P}$ was added to the ASA supported catalyst, the hydrogenation activities increased with the $\mathrm{P}$ content up to an optimum concentration of $1.0 \mathrm{wt} \%$. When USY was introduced, an increased activity was obtained under the reaction temperature of $240-280{ }^{\circ} \mathrm{C}$, which was particularly prominent at $10 \mathrm{wt} \%$ USY content. Moreover, the catalyst simultaneously promoted with $1.0 \mathrm{wt} \% \mathrm{P}$ and $10 \mathrm{wt} \%$ USY exhibited superior hydrogenation activity, selectivity of decalin and sulfur tolerance, originating from the combination of the advantages of $\mathrm{P}$ and USY with ASA.

\section{References}

1 X. Chen, A. Zhao, Z. Shao, C. Li, C. T. Williams and C. Liang, J. Phys. Chem. C, 2010, 114, 16525-16533.

2 M. Selvaraj, A. Selvamani, A. Alagarasi, M. Gurulakshmi, P. S. Krishnan, K. Suthagar and K. Shanthi, Sci. Adv. Mater., 2015, 7, 714-728.

3 B. H. Cooper and B. R. B. L. Donnis, Appl. Catal., A, 1996, 137, 203-223.

4 C. Song and X. Ma, Appl. Catal., B, 2003, 41, 207-238.

5 A. Stanislaus and B. H. Cooper, Catal. Rev.: Sci. Eng., 1994, 36, 75-123.

6 T. Kan, X. Sun, H. Wang, C. Li and U. Muhammad, Energy Fuels, 2012, 26, 3604-3611.

7 A. Nishijima, T. Kameoka, T. Sato, N. Matsubayashi and Y. Nishimura, Catal. Today, 1998, 45, 261-269.

8 F. Luck, Bull. Soc. Chim. Belg., 1991, 100, 781-800.

9 X. Carrier, J. F. Lambert and M. Che, J. Am. Chem. Soc., 1997, 119, 10137-10146.

10 M. Breysse, P. Afanasiev, C. Geantet and M. Vrinat, Catal. Today, 2003, 86, 5-16.
11 A. Corma, M. T. Navarro and J. P. Pariente, J. Chem. Soc., Chem. Commun., 1994, 147-148.

12 S. R. Kirumakki, B. G. Shpeizer, G. V. Sagar, K. V. R. Chary and A. Clearfield, J. Catal., 2006, 242, 319-331.

13 A. E. Coumans, D. G. Poduval, J. A. R. van Veen and E. J. M. Hensen, Appl. Catal., A, 2012, 411-412, 51-59.

14 A. Niquille-Röthlisberger and R. Prins, Ind. Eng. Chem. Res., 2007, 46, 4124-4133.

15 A. Corma, V. González-Alfaro and A. V. Orchillés, J. Catal., 2001, 200, 34-44.

16 B. Pawelec, R. Mariscal, R. M. Navarro, S. van Bokhorst, S. Rojas and J. L. G. Fierro, Appl. Catal., A, 2002, 225, 223237.

17 M. A. Arribas and A. Mart Nez, Appl. Catal., A, 2002, 230, 203217.

18 Q. Meng, B. Liu, J. Piao and Q. Liu, J. Catal., 2012, 290, 55-64. 19 Y. Yin, L. Qin, X. Wang, G. Wang, J. Zhao, B. Liu and Y. Chen, RSC Adv., 2016, 6, 111291-111298.

20 M. Du, Z. Qin, H. Ge, X. Li, Z. Lü and J. Wang, Fuel Process. Technol., 2010, 91, 1655-1661.

21 P. Atanasova, T. Tabakova, C. Vladov, T. Halachev and A. L. Agudo, Appl. Catal., A, 1997, 161, 105-119.

22 S. K. Maity, J. Ancheyta, M. S. Rana and P. Rayo, Catal. Today, 2005, 109, 42-48.

23 J. M. Herrera, J. Reyes, P. Roquero and T. Klimova, Microporous Mesoporous Mater., 2005, 83, 283-291.

24 R. Huirache-Acuña, B. Pawelec, E. Rivera-Muñoz, R. Nava, J. Espino and J. L. G. Fierro, Appl. Catal., B, 2009, 92, 168184.

25 J. L. G. Fierro, A. L. Agudo, N. Esquivel and R. Lopez Cordero, Appl. Catal., 1989, 48, 353-363.

26 S. Sigurdson, V. Sundaramurthy, A. K. Dalai and J. Adjaye, J. Mol. Catal. A: Chem., 2008, 291, 30-37.

27 R. Lopez Cordero, S. Lopez Guerra, J. L. G. Fierro and A. Lopez Agudo, J. Catal., 1990, 126, 8-12.

28 R. Nava, A. Infantes-Molina, P. Castaño, R. Guil-López and B. Pawelec, Fuel, 2011, 90, 2726-2737.

29 M. A. Guzmán, R. Huirache-Acuña, C. V. Loricera, J. R. Hernández, J. N. Díaz De León, J. A. de Los Reyes and B. Pawelec, Fuel, 2013, 103, 321-333.

30 D. Nicosia and R. Prins, J. Catal., 2005, 229, 424-438.

31 P. Li, C. Nan, Z. Wei, J. Lu, Q. Peng and Y. Li, Chem. Mater., 2010, 22, 4232-4236.

32 C. Shen, C. Hui, T. Yang, C. Xiao, J. Tian, L. Bao, S. Chen, H. Ding and H. Gao, Chem. Mater., 2008, 20, 6939-6944.

33 R. Chiang and R. Chiang, Inorg. Chem., 2007, 46, 369-371.

34 X. Zheng, S. Yuan, Z. Tian, S. Yin, J. He, K. Liu and L. Liu, Mater. Lett., 2009, 63, 2283-2285.

35 A. Corma, A. Martinez and V. Martinez-Soria, J. Catal., 1997, 169, 480-489.

36 T. He, Y. Wang, P. Miao, J. Li, J. Wu and Y. Fang, Fuel, 2013, 106, 365-371.

37 A. Morales, M. M. Ramirez De Agudelo and F. Hernandez, Appl. Catal., A, 1988, 41, 261-271.

38 M. Schiavello, M. L. Jacono and A. Cimino, J. Phys. Chem., 1971, 75, 1051-1057.

39 C. A. Emeis, J. Catal., 1993, 141, 347-354. 
40 J. Zhao, Y. Yin, Y. Li, W. Chen and B. Liu, Chem. Eng. J., 2016, 284, 405-411.

41 P. Castano, B. Pawelec, J. L. G. Fierro, J. M. Arandes and J. Bilbao, Fuel, 2007, 86, 2262-2274.

42 A. T. Aguayo, A. G. Gayubo, R. Vivanco, M. Olazar and J. Bilbao, Appl. Catal., A, 2005, 283, 197-207.

43 J. Wang, Q. Li and J. Yao, Appl. Catal., A, 1999, 184, 181-188. 44 C. Song and A. D. Schmitz, Energy Fuels, 1997, 11, 658-661.
45 H. Yasuda, N. Matsubayashi, T. Sato and Y. Yoshimura, Catal. Lett., 1998, 54, 23-27.

46 W. M. H. Sachtler and A. Y. Stakheev, Catal. Today, 1992, 12, 283-295.

47 H. J. Kim and C. Song, Energy Fuels, 2014, 28, 6788-6792.

48 M. Jian and R. Prins, J. Catal., 1997, 179, 18-27.

49 L. J. Simon, M. Rep, J. G. van Ommen and J. A. Lercher, Appl. Catal., A, 2001, 218, 161-170. 